\title{
Intubation with VivaSight or conventional left-sided double-lumen tubes: a randomized trial
}

\section{Intubation avec VivaSight ou tubes conventionnels à double lumière gauche: un essai randomisé}

\author{
Rolf Schuepbach, MD • Bastian Grande, MD - Giovanni Camen, MD • \\ Alexander R. Schmidt, MD • Henrik Fischer, MD • Daniel I. Sessler, MD • \\ Burkhardt Seifert, PhD • Donat R. Spahn, MD • Kurt Ruetzler, MD \\ Received: 8 September 2014/Accepted: 19 January 2015/Published online: 6 February 2015 \\ (C) Canadian Anesthesiologists' Society 2015
}

\begin{abstract}
Introduction Double-lumen endotracheal tubes (DLTs), which are commonly used for single-lung ventilation during surgery, are difficult to insert. In addition, they often move during surgical lung manipulation which can cause lifethreatening complications. Flexible bronchoscopy is used routinely to establish and confirm proper DLT placement. The newly designed VivaSight DLT has an integrated camera, allowing continuous visualization of its position in
\end{abstract}

\begin{abstract}
Author contributions Rolf Schuepbach and Bastian Grande made substantial contributions to study conception and design, acquisition of data, and manuscript writing. Giovanni Camen and Alexander $R$. Schmidt made substantial contributions to acquisition and interpretation of data and helped draft the manuscript. Henrik Fischer made substantial contributions to analysis and interpretation of data and revised the article for important intellectual content. Daniel I. Sessler made substantial contributions to study conception and design, analysis and interpretation of data, and drafting the manuscript. Burkhardt Seifert made substantial contributions to analysis and interpretation of data and revised the manuscript for intellectual content. Donat R. Spahn made substantial contributions to study conception and design and assisted with manuscript revision. Kurt Ruetzler made substantial contributions to study conception and design; acquisition of data analysis and interpretation; and was responsible for drafting the manuscript.
\end{abstract}

R. Schuepbach, MD · B. Grande, MD · A. R. Schmidt, MD .

D. R. Spahn, MD · K. Ruetzler, MD ( $\square)$

Institute of Anesthesiology, University and University Hospital

Zurich, Raemistrasse 100, 8091 Zurich, Switzerland

e-mail: kurt.ruetzler@usz.ch

URL: http://www.OR.org

G. Camen, MD

Department of Internal Medicine, Cantonal Hospital of Glarus, Glarus, Switzerland

H. Fischer, MD

Medical Department, Federal Ministry of the Interior, Vienna,

Austria the trachea. We hypothesized that the time to intubation using the VivaSight DLT would be faster than with a conventional DLT.

Methods We enrolled 40 adults scheduled for thoracic surgery. Patients were randomized to conventional DLT $(n=20)$ or VivaSight DLT $(n=20)$. Time to intubation was our primary outcome. Secondary outcomes were insertion success without flexible bronchoscopy, frequency of tube displacement, ease of insertion, quality of lung collapse, postoperative complaints, and airway injuries.

Results Time [mean (SD)] to successful intubation was significantly faster with the VivaSight DLT [63 (58) sec] compared with the conventional DLT [97(84) sec; $P=0.03]$. The VivaSight DLTs were correctly inserted during all attempts. When malpositioning of the VivaSight DLT occurred, it was easily remedied, even in the lateral position. The devices were comparable with respect to postoperative coughing, hoarseness, and sore throat. Airway injuries tended to be more common with the VivaSight DLT, although this study was underpowered for airway injuries.

D. I. Sessler, MD

Department of Outcomes Research, Cleveland Clinic, Cleveland, $\mathrm{OH}$, USA

B. Seifert, $\mathrm{PhD}$

Department of Biostatistics, Epidemiology, Biostatistics and Prevention Institute, University of Zurich, Zurich, Switzerland

K. Ruetzler, MD

Division of Cardiothoracic and Vascular Anesthesia and Intensive Care Medicine, Medical University of Vienna, Vienna, Austria 
Conclusion The VivaSight DLT camera allowed faster insertion and facilitated initial positioning. It also confirmed proper tube positioning intraoperatively and facilitated repositioning when necessary. This trial was registered at clinicaltrials.gov: NCT01807676.

\section{Résumé}

Introduction Les tubes endotrachéaux à double lumière (DLT), régulièrement utilisés pour la ventilation d'un seul poumon au cours de la chirurgie, sont difficiles à insérer. De plus, ils se déplacent souvent au cours de la manipulation chirurgicale du poumon, pouvant entraîner des complications mettant en danger la vie du patient. La bronchoscopie flexible est habituellement utilisée pour installer et confirmer le positionnement correct du DLT. Le DLT VivaSight ${ }^{\circledR}$ nouvellement conçu possède une caméra intégrée qui permet de visualiser en permanence sa position dans la trachée. Nous avons émis l'hypothèse que le temps d'intubation serait plus court à l'aide du DLT VivaSight qu'avec un DLT conventionnel.

Méthodes Nous avons recruté 40 adultes qui devaient subir une chirurgie thoracique programmée. Les patients ont été randomisés dans un groupe "DLT conventionnel " $(n=20)$ ou "DLT VivaSight» $(n=20)$. Le temps de réalisation de l'intubation était notre critère d'évaluation principal. Les critères d'évaluation secondaires étaient le taux d'insertion sans bronchoscopie flexible, la fréquence de déplacement du tube, la facilité d'insertion, la qualité du collapsus pulmonaire, les plaintes postopératoires et les lésions des voies aériennes.

Résultats Le temps (moyenne [ET]) de réussite de l'intubation a été significativement plus court avec le DLT VivaSight (63 [58] sec) qu'avec le DLT conventionnel (97 [84] sec; $P=0,03$ ). Les DLT VivaSight ont été correctement insérés au cours de toutes les tentatives. Quand un mauvais positionnement du DLT VivaSight survenait, il était facile d'y remédier, même en décubitus latéral. Les dispositifs ont été comparables pour ce qui concerne la toux postopératoire, la voix rauque et le mal de gorge. Les lésions des voies aériennes ont eu tendance à être plus fréquentes avec le DLT VivaSight bien que l'étude manquait de puissance pour évaluer ce critère.

Conclusion La caméra du DLT VivaSight a permis une insertion plus rapide et a facilité le positionnement initial. Elle a également confirmé le bon positionnement peropératoire du tube et a facilité son repositionnement quand cela était nécessaire. Cette étude a été enregistrée sur le site www.clinicaltrials.gov: NCT01807676.

Single-lung ventilation is required in several clinical situations and for various surgical procedures. Perhaps the most frequent indication is thoracic surgery during which single-lung ventilation and collapse of the operated lung facilitate the operation. Double-lumen tubes (DLTs) are the most common approach to single-lung ventilation. $^{1,2}$ The DLT consists of a proximal tracheal end and a distal bronchial end, reaching into either the left or right side of the lung. Double-lumen tubes are much larger and stiffer than conventional single-lumen tubes. Consequently, DLTs are more difficult to position properly and more likely to cause airway injuries. ${ }^{3,4}$ Patients undergoing thoracic surgery often have poor lung function and limited tolerance for apnea. Rapid, correct tube insertion is thus a priority in such patients.

The VivaSight DLT (ET-View Ltd, Misgav, Israel) is a novel single-use DLT with an embedded 2-mm video imaging device and light source at the distal end of the tracheal lumen. The VivaSight DLT connects with any standard video monitor and/or recording device using composite video baseband signal technology. The VivaSight DLT has an $85^{\circ}$ diagonal field-of-view complementary metal oxide semiconductor (CMOS) image sensor. The resolution of the camera is common intermediate format (CIF) $320 \times 240$ (76,800 pixels), and the image sensitivity is $0.7 \mathrm{~V} / \mathrm{lux} \times \mathrm{sec}$ ). The VivaSight DLT also has an integrated flushing system that helps keep the camera lens clean. When correctly positioned, the video imaging device is focused on the carina, providing visual confirmation of the bronchial cuff in the left main bronchus.

Unlike a conventional DLT, the VivaSight DLT provides continuous surveillance throughout the surgical procedure, allowing early identification of tube displacement. Our goal was to determine the clinical performance and feasibility of this new device compared with a conventional DLT. Specifically, we tested our primary hypothesis that intubation, including visual confirmation of correct positioning, is faster with the VivaSight DLT than with a conventional DLT. Secondary endpoints were the proportion of correct insertions without requiring flexible bronchoscopy, frequency of tube displacement, ease of insertion, quality of lung collapse, and postoperative complaints and airway injuries.

\section{Methods}

The Ethics Committee of the Kanton Zurich, Zurich, Switzerland approved this study (Ref. 2012-0520; Chairperson Prof. Edith Schmidt) on March 14, 2013. This study was registered at clinicaltrials.gov (NCT01807676).

After obtaining their written consent, we enrolled 40 adults who were to undergo elective thoracic surgery that required single-lung ventilation between July and 
December 2013 (Fig. 1). We excluded patients more than $90 \mathrm{yr}$ of age and those with American Society of Anesthesiologists physical status IV or $\mathrm{V}$, a body mass index $>45 \mathrm{~kg} \cdot \mathrm{m}^{-2}$, and/or any contraindications to use of a left-sided 37-Fr double-lumen tube. Patients who had had thoracic surgery within the last four weeks, a systemic infection or suspected tuberculosis, or had been previously diagnosed with or suspected of having a difficult airway were also excluded.
At the time of execution of this study, only the 37-Fr VivaSight DLT was commercially available. We included only patients who required a 37-Fr DLT in this study based on preoperative clinical assessments. The VivaSight DLT is now available in sizes 35, 37, 39, and 41 Fr (Fig. 2).

Patients were premedicated with $7.5 \mathrm{mg}$ oral midazolam. An arterial catheter was used to supplement standard anesthetic monitoring. Patients were preoxygenated for at least two minutes, and general anesthesia was induced with

\section{CONSORT 2010 Flow Diagram}

Intubation with VivaSight or Conventional Left-Sided Double Lumen Tubes: A Randomized Trial

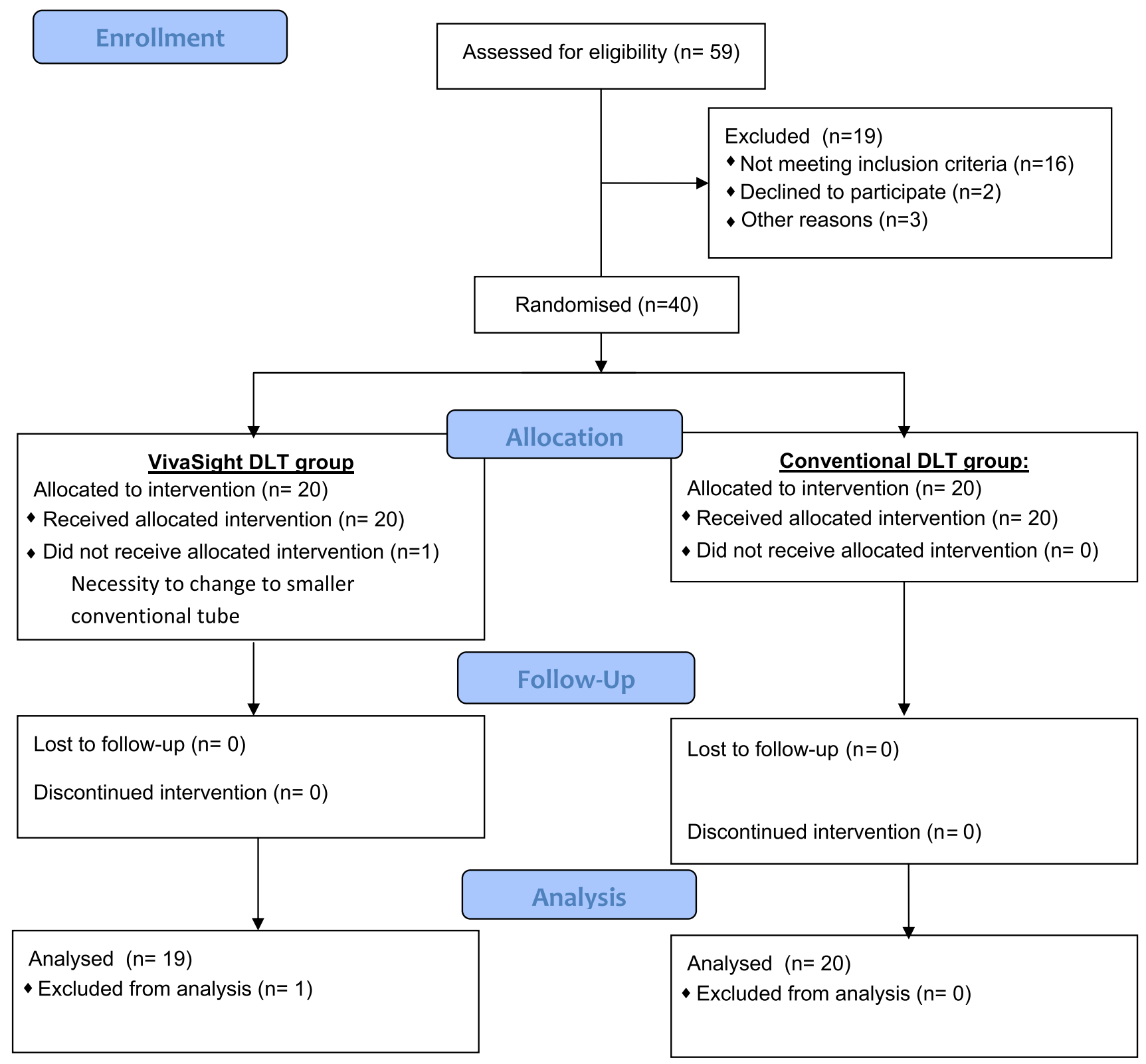

Fig. 1 Participant enrolment and retention 


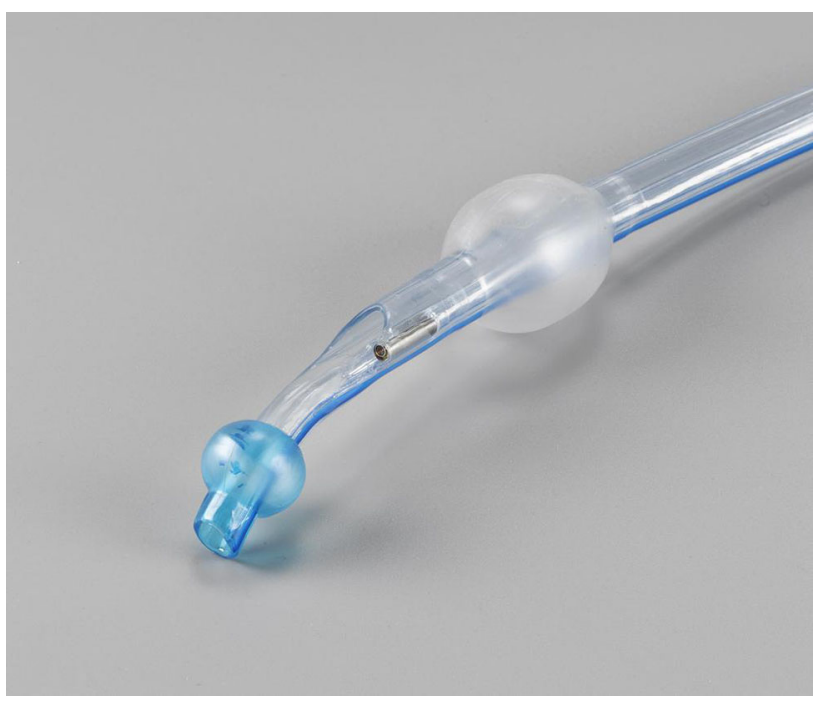

Fig. 2 VivaSight DLT. The optical sensor is seen at the junction of tracheal and bronchial lumens. Image reproduced with permission from ET-View Medical Ltd, Misgav, Israel

fentanyl $\approx 3 \mu \mathrm{g} \cdot \mathrm{kg}^{-1}, \quad$ propofol $\approx 1.5 \mathrm{mg} \cdot \mathrm{kg}^{-1}, \quad$ and rocuronium $\approx 0.6 \mathrm{mg} \cdot \mathrm{kg}^{-1}$ or atracurium $\approx 0.2 \mathrm{mg} \cdot \mathrm{kg}^{-1}$. Additional propofol was given as necessary. Complete muscle relaxation was confirmed by the absence of palpable twitches in response to supra-maximum train-of-four stimulation of the ulnar nerve at the wrist. All patients were intubated in the supine position.

The patients were randomly assigned 1:1 without stratification or blocking to a VivaSight DLT or conventional DLT (Broncho-Cath, left sided; Ruesch, Kernen, Germany). Randomization was based on computer-generated codes that were kept in sequentially numbered opaque envelopes. The envelopes were opened shortly before induction of anesthesia by an independent investigator.

Patients assigned to the VivaSight DLT group were intubated with a 37-Fr left-sided VivaSight DLT connected to a display monitor. With the assistance of a conventional Macintosh laryngoscope, the tube was inserted into the mouth. Thereafter, insertion was guided by the view on the video monitor. When the tube passed the vocal cords, it was rotated $90^{\circ}$ toward the left and advanced until the main carina was visible on the monitor.

Patients assigned to the conventional DLT-group were intubated with a 37-Fr left-sided DLT. The DLT was introduced into the trachea using a conventional Macintosh laryngoscope. After passing the vocal cords, the DLT was rotated $90^{\circ}$ toward the left and advanced until slight resistance was met. Tube position was verified using flexible bronchoscopy.

Correct tube placement was confirmed by auscultation. Neither tube was equipped with a carina hook, and neither was lubricated. All intubation procedures were performed by one of four highly experienced thoracic anesthetists, each having considerable experience using DLTs. The endotracheal tube cuffs were inflated with air to $20-25 \mathrm{mmHg}$, as necessary, to maintain an adequate seal. The tube position of the conventional DLT was verified in each case using flexible bronchoscopy with the patient in the supine position and then turned to a lateral position. An independent investigator evaluated tube displacements and time for accomplishing intubation. The latter was defined as the time from insertion of the laryngoscope to confirmation of placement by auscultation. The anesthesiologist performing the intubation reported a subjective assessment of procedural difficulty with the designated device (1: very easy; 2 : easy; 3 : medium; 4 : poor; 5: impossible).

General anesthesia was primarily maintained with sevoflurane. Patients' lungs were ventilated with $\mathrm{O}_{2}$ in air, usually with an inspired oxygen fraction $\left(\mathrm{F}_{1} \mathrm{O}_{2}\right)$ of $\approx 80 \%$. Additional oxygen was provided as clinically necessary, especially during single-lung ventilation. Endtidal $\mathrm{CO}_{2}$ was maintained as closely as was clinically feasible between 32 and $35 \mathrm{mmHg}$.

As single-lung ventilation became required during the operation, the bronchial cuff was inflated. After opening the pleura and directly examining the lungs, the thoracic surgeons rated the extent of the lung collapse - which is relevant for performing atraumatic surgery - as follows: $1=$ excellent (complete collapse with perfect surgical exposure; 2 = fair (total collapse but some residual air in the lung); $3=$ poor (no or partial collapse with possible interference during the surgical procedure).

About 30 min before completion of the surgery, patients were given $1 \mathrm{~g}$ paracetamol intravenously. When surgery ended, the patient was turned supine, and the DLT was removed. Thereafter, an appropriately sized conventional laryngeal mask was inserted. An investigator, blinded to the group assignment, inserted a flexible bronchoscope via the laryngeal mask airway to search for bronchial or pharyngolaryngeal injuries using established criteria and scoring. ${ }^{5}$ Patients were then extubated if clinically appropriate and transferred to the postanesthesia care unit (PACU) where they remained for at least two hours. The duration of intubation, defined as the time from insertion of the laryngoscope until extubation of the DLT, was documented.

An investigator, blinded to the tube assignments, asked patients $24 \mathrm{hr}$ after surgery if they had a sore throat, hoarseness, or coughing. Sore throat was defined as continuous throat pain and was rated: $0=$ no pain; $1=$ mild (pain with deglutition); $2=$ moderate (pain present constantly and increasing with deglutition); $3=$ severe (pain interfering with eating and requiring 
analgesic medication). Hoarseness was defined as an acoustic quality that was different from the previous voice quality of that patient. It was classified into two categories (yes or no). If the answer was yes, the intensity of the hoarseness was graded on a scale of one to three as follows: $1=$ noticed by patient; $2=$ obvious to observer; $3=$ aphonia. Postoperative coughing was assessed using an established scoring system: If the answer was yes, the intensity of coughing was graded on a scale of one to three as follows: $1=$ mild; $2=$ moderate; $3=$ severe.

\section{Statistical analysis}

Time to intubation was our primary outcome. Secondary outcomes included insertion success without use of flexible bronchoscopy, frequency of tube displacement, ease of insertion, quality of lung collapse, and postoperative complaints and airway injuries. Continuous variables were compared using the Mann-Whitney test. Categorical data were compared using the Chi-square test with exact $P$ values (ease of insertion, degree of coughing, hoarseness, sore throat), or Fisher's exact test (insertion without use of flexible bronchoscopy, tube displacement during positioning, tube displacement during surgical lung manipulation, use of fibreoptic bronchoscopy during surgery, degree of lung collapse). The difference between the medians of duration of intubation procedures was assessed using the Hodges-Lehman estimator.

Sample size was estimated a priori based on the unpaired $t$ test using the assumption that $100(30) \mathrm{sec}$ would be required to position a conventional DLT. ${ }^{6,7} \mathrm{We}$ further assumed that the experimental tube would speed insertion by $30 \mathrm{sec}$, which would represent a (marginally) clinically important time saving. Based on the power of 0.8 and an alpha error of 5\%, we expected to identify a statistically significant difference after 34 patients. We thus decided to enrol 40 patients to accommodate dropouts after randomization.

All analyses were performed with IBM SPSS Statistics, Version 21.0 (IBM Corp., Armonk, NY, USA). $P$ values $<0.05$ were considered to indicate statistical significance.

\section{Results}

Twenty patients were enrolled in each group. One patient in the VivaSight DLT group was excluded because placement of the 37-Fr tube was unsuccessful, and the patient had to be intubated with a conventional 35-Fr DLT. The remaining 39 patients completed the study and were included in our analysis. Patients in the conventional DLT
Table 1 Baseline characteristics

\begin{tabular}{lll}
\hline & DLT $(n=20)$ & $\begin{array}{l}\text { VivaSight DLT } \\
(n=20)\end{array}$ \\
\hline Included & 20 & 20 \\
Removed & 0 & 1 \\
Male sex & 10 & 9 \\
Bilateral surgery & 2 & 5 \\
Right lung & 12 & 10 \\
Left lung & 6 & 5 \\
Age (yr) & $63(10)$ & $57(17)$ \\
Weight (kg) & $72(13)$ & $66(13)$ \\
Height (cm) & $172(7)$ & $168(6)$ \\
Body mass index $\left(\mathrm{kg} \cdot \mathrm{m}^{-2}\right)$ & $24(3)$ & $23(4)$ \\
Pack-years smoking & $12(16)$ & $11(18)$ \\
ASA I & 1 & 2 \\
ASA II & 7 & 9 \\
ASA III & 12 & 9
\end{tabular}

Continuous data are presented as the mean \pm standard deviation

ASA $=$ American Society of Anesthesiologists physical status; DLT $=$ double-lumen tube

group tended to be slightly heavier, older, and larger (Table 1).

Our primary outcome - time [mean (SD)] from insertion of the laryngoscope to confirmation of placement by auscultation - was significantly faster with the VivaSight DLT [63 (58) sec] than with the conventional DLT [97 (84) sec; $P=0.03$ ] (Table 2), with a median difference of $34 \mathrm{sec}$ (95\% confidence interval [CI]: 2 to $46 \mathrm{sec})$.

Flexible bronchoscopy indicated that conventional DLTs were properly positioned in 17 of 20 DLT intubations $(85 \%)$, whereas video-guided intubation was successfully in 19 of 19 VivaSight DLT intubations $(100 \%)$. Four of the conventional DLTs became displaced during placement and another two during surgical lung manipulation, each requiring repositioning under fibreoptic bronchoscopy. In the VivaSight DLT group, tube displacement was detected in two patients during placement and in three of 19 cases during surgical lung manipulation. Repositioning was successful without the use of flexible bronchoscopy in all cases. Ease of insertion, quality of lung collapse, and duration of intubation were comparable in the two groups (Table 2).

The two devices were also comparable with respect to patients' subjective complaints, such as coughing, hoarseness, and/or a sore throat (Table 3). Airway injuries - diagnosed by postsurgical fibreoptic bronchoscopy - are shown in Table 4. The injuries were minor but tended to be more common in the VivaSight DLT patients. 
Table 2 Outcomes

\begin{tabular}{llll}
\hline & $\begin{array}{l}\text { DLT } \\
(n=20)\end{array}$ & $\begin{array}{l}\text { VivaSight } \\
\text { DLT } \\
(n=19)\end{array}$ & $P$ \\
\hline $\begin{array}{l}\text { Primary Outcome } \\
\text { Intubation time (sec) }\end{array}$ & $97(84)$ & $63(58)$ & 0.03 \\
$\begin{array}{l}\text { Secondary Outcomes } \\
\text { Intubation without flexible }\end{array}$ & $17(85 \%)$ & $19(100$ & 1.00 \\
bronchoscopy & & $\%)$ & \\
Tube dislocation during placement & $4(20 \%)$ & $2(11 \%)$ & 0.66 \\
Tube dislocation during surgery & $2(10 \%)$ & $3(16 \%)$ & 1.00 \\
Ease of insertion & & & \\
1 & $13(65 \%)$ & $13(65 \%)$ & 0.87 \\
2 & $3(15 \%)$ & $3(15 \%)$ & \\
3 & $3(15 \%)$ & $1(5 \%)$ & \\
4 & $1(5 \%)$ & $2(10 \%)$ & \\
5 & 0 & 1 & \\
(excluded) & & & \\
Lung collapse quality & & & \\
1 & $18(90 \%)$ & $16(84 \%)$ & 0.36 \\
2 & $2(10 \%)$ & $3(16 \%)$ & \\
3 & 0 & 0 & $144 \pm 75$ \\
Intubation duration (min) & $155 \pm 104$ & 0.87 \\
\hline
\end{tabular}

Continuous data are presented as mean \pm standard deviation. Categorical data are presented as absolute values (\%). $\mathrm{DLT}=$ double lumen tube

Table 3 Postoperative complaints

\begin{tabular}{|c|c|c|c|}
\hline & $\operatorname{DLT}(n=20)$ & VivaSight DLT $(n=19)$ & $P$ \\
\hline \multicolumn{3}{|c|}{ Coughing } & \multirow[t]{5}{*}{0.53} \\
\hline 0 & $14(70 \%)$ & $12(63 \%)$ & \\
\hline 1 & $6(30 \%)$ & $5(26 \%)$ & \\
\hline 2 & 0 & $2(11 \%)$ & \\
\hline 3 & 0 & 0 & \\
\hline \multicolumn{3}{|c|}{ Hoarseness } & \multirow[t]{5}{*}{0.7} \\
\hline 0 & $13(65 \%)$ & $10(52 \%)$ & \\
\hline 1 & $3(15 \%)$ & $7(37 \%)$ & \\
\hline 2 & $4(20 \%)$ & $2(11 \%)$ & \\
\hline 3 & 0 & 0 & \\
\hline \multicolumn{3}{|c|}{ Sore throat } & \multirow[t]{5}{*}{0.39} \\
\hline 0 & $11(55 \%)$ & $8(42 \%)$ & \\
\hline 1 & $8(40 \%)$ & $9(47 \%)$ & \\
\hline 2 & $1(5 \%)$ & $2(11 \%)$ & \\
\hline 3 & 0 & 0 & \\
\hline
\end{tabular}

DLT $=$ double lumen tube

\section{Discussion}

This study compared the clinical performance of the VivaSight DLT with that of a conventional DLT. Our
Table 4 Airway injuries (diagnosed by flexible bronchoscopy)

\begin{tabular}{|c|c|c|c|c|}
\hline \multirow[t]{2}{*}{ Injury } & \multicolumn{2}{|c|}{ DLT $(n=20)$} & \multicolumn{2}{|c|}{ VivaSight DLT $(n=19)$} \\
\hline & Small lesion & Large lesion & Small lesion & Large lesion \\
\hline \multicolumn{5}{|l|}{ Vocal cord } \\
\hline Thickening & 3 & 0 & 5 & 0 \\
\hline Redness & 2 & 0 & 3 & 1 \\
\hline Edema & 5 & 0 & 5 & 1 \\
\hline Erythema & 1 & 0 & 2 & 0 \\
\hline Hematoma & 2 & 0 & 3 & 0 \\
\hline Bleeding & 1 & 0 & 1 & 1 \\
\hline Granuloma & 0 & 0 & 0 & 0 \\
\hline Arytenoids & 0 & 0 & 0 & 0 \\
\hline \multicolumn{5}{|l|}{ Trachea } \\
\hline Redness & 6 & 0 & 12 & 0 \\
\hline Edema & 0 & 0 & 1 & 0 \\
\hline Hematoma & 3 & 0 & 2 & 0 \\
\hline Bleeding & 5 & 0 & 8 & 1 \\
\hline \multicolumn{5}{|l|}{ Bronchus } \\
\hline Redness & 6 & 0 & 4 & 0 \\
\hline Edema & 1 & 0 & 1 & 0 \\
\hline Hematoma & 2 & 0 & 1 & 0 \\
\hline Bleeding & 4 & 1 & 5 & 0 \\
\hline \multicolumn{5}{|l|}{ Main carina } \\
\hline Redness & 0 & 0 & 2 & 0 \\
\hline Edema & 1 & 0 & 1 & 0 \\
\hline Hematoma & 2 & 0 & 2 & 0 \\
\hline Bleeding & 1 & 1 & 4 & 1 \\
\hline Cumulative* & 45 & 2 & 62 & 5 \\
\hline
\end{tabular}

Data are presented as absolute values. $*$ In some patients, multiple lesions have been described

DLT $=$ double lumen tube

primary finding was that the VivaSight DLT could be correctly positioned 34 (95\% CI 2 to 46$)$ sec faster. The rates of tube displacements were similar for the two devices, but the VivaSight DLT could be repositioned without use of flexible bronchoscopy.

Previous studies have reported intubation times with conventional DLTs at 85-128 sec, including fibreoptic bronchoscopy confirmation of proper positioning. ${ }^{6,7}$ Time to intubation in our patients was $97 \mathrm{sec}$ with conventional DLT but only $63 \mathrm{sec}$ using the VivaSight DLT. This difference was statistically significant, but it is probably is only a small - although potentially clinically important improvement

Double-lumen tubes often become displaced after repositioning patients from the supine (intubating) to the lateral (operating) position. If not promptly identified and remedied, displacements can result in life-threatening complications and airway lacerations. ${ }^{9}$ Clinical signs of 
displacement include rising airway pressure, oxygen desaturation, and/or difficulty performing single-lung ventilation. Immediate verification of tube position using fibreoptic bronchoscopy is required in such cases. ${ }^{8}$ Correct positioning of DLTs must be confirmed using flexible bronchoscopy. ${ }^{8}$ Handling the flexible bronchoscope requires a high level of experience as well as the infrastructure for cleaning and maintaining these fragile instruments. $^{10,11}$ Continuous visualisation potentially provides earlier identification and correction of endobronchial displacement.

Conventional DLTs were correctly positioned without use of flexible bronchoscopy in 17 of our 20 cases. This result is consistent with previous studies. ${ }^{11,12}$ Although insertion without use of flexible bronchoscopy was often successful, it failed about $15 \%$ of the time, clearly supporting the current standard of confirming DLT position with flexible bronchoscopy. ${ }^{6,8,13-16}$ In contrast, flexible bronchoscopy was unnecessary with the VivaSight DLT because a camera is incorporated into the tube.

The benefit of an incorporated video camera was especially evident while the patients were being repositioned laterally and during surgical lung manipulation. For example, the conventional DLT became displaced in four of 20 of our patients during the lateral turning and in two more during surgical lung manipulation. A comparable number of the VivaSight DLTs also became malpositioned, but it was easily detected and remedied using the incorporated video camera, even with patients in the lateral position. Successful intubation, rapid detection of malpositioning, and rapid repositioning without the need for an external fibreoptic scope may be the major advantage of the VivaSight DLT.

As might be expected, both DLTs provided comparable lung collapse and were similarly rated by independent surgeons. The number of airway injuries in the conventional DLT group was similar to that reported by Mourisse et $a .^{5}{ }^{5}$ Results of our study suggest that minor airway injuries (e.g., tracheal redness, tracheal bleeding, carinal bleeding) tended to be more common in the VivaSight DLT group. This may result from the larger outer diameter of the VivaSight DLT. Our study, however, was not powered to evaluate airway injuries.

Sore throat, hoarseness, and coughing are common complaints after endotracheal intubation, especially with DLTs. ${ }^{17}$ The tube size is an important factor. ${ }^{18,19}$ In prior studies, the reported incidence of sore throat was 14-90\% and that of hoarseness $10-50 \% .^{6,18,20-22}$ This wide range may be due to variations in the skill and experience levels of the performing physicians along with predisposing factors such as the patient's sex, the cuff design, excessive cuff pressure, use of succinylcholine, type of surgery, preexisting tracheal disease, more forceful laryngoscopy, prolonged laryngoscopy, and laryngeal exposure. The incidence of coughing was comparable for the two devices we tested. In contrast, hoarseness and sore throat were more common in patients intubated with the VivaSight DLT, although the intensity was comparable in patients who experienced either complication. Again, though, our study was insufficiently powered for these outcomes.

In our hospital, the direct cost of using the conventional DLT is about USD $\$ 150$, whereas use of the VivaSight DLT costs about USD $\$ 300$. However, there is a substantial (but difficult to quantify) cost of maintaining and cleaning flexible bronchoscopes that probably exceeds USD \$100 per case. ${ }^{23}$ Direct costs vary enormously from one country to another and among hospitals. Therefore, clinicians should obtain local information when making cost-benefit decisions.

Although our study was well powered for our primary outcome (intubation time), an important limitation of the study was its low power for detecting clinically important differences regarding side effects, airway injuries, ease of insertion, and propensity for displacement. It was impossible to blind investigators because of the nature of the two tubes. There is thus potential for clinical bias toward one device or the other.

In summary, successfully insertion of the VivaSight DLT was faster than for a conventional double-lumen tube. Moreover, malpositioning was quickly detected and easily corrected without the need for additional flexible bronchoscopy. Continuous visualisation of double-lumen tube position thus appears to provide clinical benefit.

Acknowledgements We thank Professor Beatrice Beck-Schimmer, MD and Julio Moral, MD, who helped implement and conduct this study.

Conflicts of interest All authors declare that there are no potential competing interests, include financial interests, relating to patents and/or share holdings in corporations involved in the development and/or marketing of the medical device evaluated in our study.

\section{References}

1. Benumof JL, Partridge BL, Salvatierra C, Keating J. Margin of safety in positioning modern double-lumen endotracheal tubes. Anesthesiology 1987; 67: 729-38.

2. Lewis JW Jr, Serwin JP, Gabriel FS, Bastanfar M, Jacobsen G. The utility of a double-lumen tube for one-lung ventilation in a variety of noncardiac thoracic surgical procedures. J Cardiothorac Vasc Anesth 1992; 6: 705-10.

3. Liu H, Jahr JS, Sullivan E, Waters PF. Tracheobronchial rupture after double-lumen endotracheal intubation. J Cardiothorac Vasc Anesth 2004; 18: 228-33.

4. Yuceyar L, Kaynak K, Canturk E, Aykac B. Bronchial rupture with a left-sided polyvinylchloride double-lumen tube. Acta Anaesthesiol Scand 2003; 47: 622-5. 
5. Mourisse J, Liesveld J, Verhagen A, et al. Efficiency, efficacy, and safety of EZ-blocker compared with left-sided double-lumen tube for one-lung ventilation. Anesthesiology 2013; 118: 550-61.

6. Ruetzler K, Grubhofer G, Schmid W, et al. Randomized clinical trial comparing double-lumen tube and EZ-Blocker for singlelung ventilation. Br J Anaesth 2011; 106: 896-902.

7. Campos JH, Kernstine KH. A comparison of a left-sided Broncho-Cath with the torque control blocker univent and the wire-guided blocker. Anesth Analg 2003; 96: 283-9.

8. Cohen E. Double-lumen tube position should be confirmed by fiberoptic bronchoscopy. Curr Opin Anaesthesiol 2004; 17: 1-6.

9. Owen RL, Cheney $F W$. Endobronchial intubation: a preventable complication. Anesthesiology 1987; 67: 255-7.

10. Kirkpatrick MB, Smith JR, Hoffman PJ, Middleton RM 3rd. Bronchoscope damage and repair costs: results of a regional postal survey. Respir Care 1992; 37: 1256-9.

11. Mehta AC, Curtis PS, Scalzitti ML, Meeker DP. The high price of bronchoscopy. Maintenance and repair of the flexible fiberoptic bronchoscope. Chest 1990; 98: 448-54.

12. Heir JS, Purugganan R, Jackson TA, et al. A retrospective evaluation of the use of video-capable double-lumen endotracheal tubes in thoracic surgery. J Cardiothorac Vasc Anesth 2014; 28: 882-4.

13. Campos JH. Progress in lung separation. Thorac Surg Clin 2005; 15: 71-83.

14. Brodsky JB, Lemmens HJ. Left double-lumen tubes: clinical experience with 1,170 patients. J Cardiothorac Vasc Anesth 2003; 17: $289-98$
15. Slinger $P$. A view of and through double-lumen tubes. J Cardiothorac Vasc Anesth 2003; 17: 287-8.

16. Benumof $J L$. The position of a double-lumen tube should be routinely determined by fiberoptic bronchoscopy. J Cardiothorac Vasc Anesth 1993; 7: 513-4.

17. Lehmann $M$, Monte $K$, Barach $P$, Kindler $C H$. Postoperative patient complaints: a prospective interview study of 12,276 patients. J Clin Anesth 2010; 22: 13-21.

18. McHardy FE, Chung F. Postoperative sore throat: cause, prevention and treatment. Anaesthesia 1999; 54: 444-53.

19. Stout DM, Bishop MJ, Dwersteg JF, Cullen BF. Correlation of endotracheal tube size with sore throat and hoarseness following general anesthesia. Anesthesiology 1987; 67: 419-21.

20. Christensen AM, Willemoes-Larsen H, Lundby L, Jakobsen KB. Postoperative throat complaints after tracheal intubation. Br J Anaesth 1994; 73: 786-7.

21. Maruyama K, Sakai H, Miyazawa H, et al. Sore throat and hoarseness after total intravenous anaesthesia. Br J Anaesth 2004; 92: 541-3.

22. Ruetzler K, Fleck $M$, Nabecker $S$, et al. A randomized, doubleblind comparison of licorice versus sugar-water gargle for prevention of postoperative sore throat and postextubation coughing. Anesth Analg 2013; 117: 614-21.

23. Liu SS, Brodsky JB, Macario A. Cost identification analysis of anesthesia fiberscope use for tracheal intubation. J Anesth Clin Res 2012; DOI:10.4172/2155-6148.1000215. 